\title{
A Study on the Demand for Elderly Oral Health Educational Media Based on Community Healthcare
}

\author{
Jung-Eun Park ${ }^{1}$, Ji-Liang Kim² ${ }^{2}$ Jong-Hwa Jang ${ }^{1,2}$ \\ ${ }^{1}$ Department of Dental Hygiene, College of Health Science, Dankook University, Cheonan, Korea \\ ${ }^{2}$ Department of Public Health, Graduate School, Dankook University, Cheonan, Korea
}

Objectives: The socio-economic expenses of supporting the elderly are increasing with the entry of a super-aged society. Accordingly, the demand for elderly care has increased rapidly, and the community care policy has been on the agenda in Korea due to the need for a review of health policies. The purpose of this study was to recognize the demand for elderly oral health educational media as a way of visiting oral healthcare based on community healthcare.

Methods: A questionnaire survey was administered to 193 dental hygienists and health education managers from November 20 to December 10, 2020. We analyzed results with multiple response frequency analysis and chi-squared test analysis using the SPSS Windows version 20.0 (SPSS Corp., Armonk, NY, USA).

Results: As for types of media required for elderly oral healthcare education, the model utilization was the highest at $36.6 \%$, followed by video at $31.8 \%$, photo at $8.8 \%$. As a result of survey on the necessary education contents, denture care was the highest at $22.8 \%$, and periodontal tissue care at $21.1 \%$, followed by halitosis control and oral prophylaxis. An appropriate operation time was found to vary depending on the education experience of participants and the status of elderly oral health project participation. The persons with educational experience judged the education for 20-30 min suitable at 48 (52.7\%) while the persons with no educational experience judged the education for under 20 min suitable at $36(76.6 \%)(<0.001)$.

Conclusions: The oral healthcare education media for elderly showed the high demand on real materials, visual and auditory materials such as model utilization and video. And it seems that operation time and contents of oral healthcare education should be adjusted and performed depending on the status of elderly perception ability.

Keywords: Community healthcare, dental care for aged, dental health surveys, oral health education

Acknowledgments: This study was carried out with the support of the 2020 Civilian Routine Support Project from the Ministry of Health and Welfare.

Copyright (C) 2021. Korean Academy of Preventive Dentistry. All rights reserved.

This is an Open Access article distributed under the terms of the Creative Commons Attribution Non-Commercial License (http://creativecommons.org/licenses/ by-nc/4.0) which permits unrestricted non-commercial use, distribution, and reproduction in any medium, provided the original work is properly cited. 